University of Zurich

Department of Economics

Working Paper Series

ISSN 1664-7041 (print)

ISSN 1664-705X (online)

Working Paper No. 272

\title{
An Overlapping Generations Model for Monetary Policy Analysis
}

Samuel Huber and Jaehong Kim

December 2017 


\title{
An Overlapping Generations Model for Monetary Policy Analysis*
}

\author{
Samuel Huber \\ University of Basel
}

\author{
Jaehong Kim \\ Xiamen University
}

December 29, 2017

\begin{abstract}
We integrate an overlapping generations model into a new monetarist framework and show that the Friedman rule is not optimal. This is because inflation makes saving for retirement less attractive, such that young agents optimally choose to increase their consumption at the expense of lower savings. On the other hand, old agents consume less due to the inflation tax. We show that for low inflation rates, the former effect dominates the latter, such that the Friedman rule is not optimal. However, this effect disappears for higher inflation rates such that the optimal rate is at an intermediate level.
\end{abstract}

Keywords: Overlapping generations, monetary theory, Friedman rule. JEL Classification: D90, E31, E41, E50.

\section{Introduction}

In order to improve welfare, central banks seek to choose the optimal short-term nominal interest rate. In practice, this optimal interest rate is believed to be at an intermediate positive level, while theory has suggested for a long time that the Friedman (1969) rule is optimal, i.e., where nominal interest rates equal zero. Yet, theory has developed since Milton Friedman's seminal contribution, and the incorporation of additional frictions has allowed to justify a positive optimal nominal interest rate. We contribute to this theoretical literature by showing that only one additional assumption is necessary to achieve a welfare-improving role of inflation in the well-known Lagos and Wright (2005) framework and that the optimal inflation rate is at an intermediate level. ${ }^{1}$ Concretely, we integrate an overlapping generations structure and assume

\footnotetext{
${ }^{*}$ We would like to thank Aleksander Berentsen, Randall Wright, and Cyril Monnet for very helpful comments. Samuel Huber is a research fellow at the Department of Economic Theory, University of Basel. E-mail: samuel_h@gmx.ch. Jaehong Kim is an associate professor at the Wang Yanan Institute for Studies in Economics and the School of Economics, Xiamen University. E-mail: jaehongkim@xmu.edu.cn.

${ }^{1}$ In our model, the nominal interest rate satisfies the Fisher equation. Therefore, it is equivalent for the central bank to set the nominal interest rate or the inflation rate.
} 
that old/retired agents suffer a higher disutility of labor than young agents. As natural as this assumption seems, it turns out to have non-trivial implications concerning monetary policy.

In our model, agents can choose to save money for their retirement in order to benefit from their lower disutility when young. The lower the opportunity cost of holding money is (i.e., the lower nominal interest rates are), the less costly it is to save money. Therefore, agents reduce their consumption when young in order to increase their precautionary savings for retirement. Increasing the opportunity cost of holding money induces agents to reduce their savings; i.e., to increase their consumption when young. In contrast to this, old agents consume less when inflation increases, since they bear the inflation tax. We show that for low nominal interest rates, the former effect dominates the latter and thereby produces a welfare-enhancing role of inflation. However, we also show that this effect disappears for higher inflation rates, such that both young and old agents consume less as inflation increases further. Therefore, the optimal inflation rate is at an intermediate level.

We are not the first to show that it can be welfare-improving to increase inflation above the Friedman rule. For instance, the monetary models of Bewley $(1980,1983)$ show that inflation can be welfare-improving due to its distributional effects. ${ }^{2}$ While some search models of money also feature distributional effects, this welfare-enhancing role of inflation is generally absent in models that build on Lagos and Wright (2005) due to the assumption of quasi-linear preferences. $^{3}$ However, for instance, by endogenizing participation decisions, several studies find a positive relationship between inflation and welfare in the Lagos and Wright (2005) framework. ${ }^{4}$ There are also several studies that use overlapping generations models, which find that certain frictions produce a welfare-improving role of inflation. Beginning with the seminal contribution by Grandmont (1985) which assumes differences in risk aversion, more recent studies assume financial intermediation and limited communication, or type-dependent lump-sum transfers of money. ${ }^{5}$

In standard overlapping generations models, increasing inflation hurts old agents, but benefits young agents (e.g., Grandmont, 1985). However, we find that this result does not hold anymore in our model when the inflation rate exceeds a certain threshold. Hence, when inflation is sufficiently high, increasing inflation lowers consumption for both young and old agents (e.g., Lagos and Wright, 2005). It should therefore be clear that our mechanism is very different from previous studies and has nothing to do with the distributional effect of inflation.

\footnotetext{
${ }^{2}$ Also see Levine (1991) and Kehoe et al. (1992).

${ }^{3}$ See, for instance, Chiu and Molico (2014); Deviatov and Wallace (2001); Menzio et al. (2013); Molico (2006) and Rocheteau et al. (2015a) about the distributional effects of inflation in search models.

${ }^{4}$ Here, we refer to Rocheteau and Wright $(2005,2009)$ and Rocheteau and Rodriguez-Lopez (2014). See also Cooley and Quadrini (2004) for a framework where money is introduced via cash-in-advance and Berentsen et al. (2007), who endogenize participation decisions in a model which builds on Shi (1997). Others integrate more rounds of trade in the Kiyotaki-Wright market, relax the assumption of quasi linear preferences, integrate limited access to credit, or introduce additional frictions to the Arrow-Debreu market, such as limiting agents' endowment of labor or limiting their participation to this market. See, for instance, Berentsen et al. (2005); Chiu and Molico (2010, 2011); Gomis-Porqueras and Sanches (2013); Rocheteau et al. (2015b) and Williamson (2006).

${ }^{5}$ See, for instance, Bhattacharya et al. (2005); Schreft and Smith (1997, 2002); Smith (2002) and Zhu (2008). We present more details of Grandmont's framework and compare it to our model in the discussion section.
} 


\section{Environment}

Time is discrete and the economy is populated by overlapping generations who live for two periods. In each period, there are two markets that open sequentially. The first market is a centralized market, where agents produce and consume a general good and rebalance their money holdings. The second market is a goods market, where agents produce or consume a specialized good. Both goods are perishable, which rules out any form of commodity money.

At the beginning of each period, a generation $g_{t}$ of young agents is born, where the timesubscript $t$ denotes the period of birth. Young agents are born without any endowment. The measure of old agents equals $g_{t-1}$.

The centralized market is frictionless and agents consume and produce the general good. They enjoy utility $U(x)$ from $x$ consumption, where $U^{\prime}(x),-U^{\prime \prime}(x)>0, U^{\prime}(0)=\infty$, and $U^{\prime}(\infty)=0$. The linear production technology transforms $\ell$ units of labor into $\ell$ units of the general good, which produces a disutility of labor. We assume that the disutility of labor differs between age and that old agents suffer a higher disutility than young agents. Equivalently, this can be interpreted as old agents having a higher utility of leisure. We assume that the disutility of old agents equals $\mu \ell$, where $\mu>1$. The disutility of young agents is given by $f(\ell)$, where $f$ is in $C^{2}(\mathbb{R}), f(0)=0, f^{\prime \prime}(\ell) \geq 0$, and

$$
\begin{cases}f^{\prime}(\ell)=1, & \text { for } \ell \leq \mathfrak{L}-\varepsilon, \\ f^{\prime}(\ell) \in(1, \mu), & \text { for } \mathfrak{L}-\varepsilon<\ell<\mathfrak{L}+\varepsilon \\ f^{\prime}(\ell)=\mu, & \text { for } \ell \geq \mathfrak{L}+\varepsilon,\end{cases}
$$

for some $\mathfrak{L}>0$ and small $\varepsilon>0$. Figure 1 stylistically shows the evolution of the disutility of labor of young and old agents as a function of units of labor $\ell$.

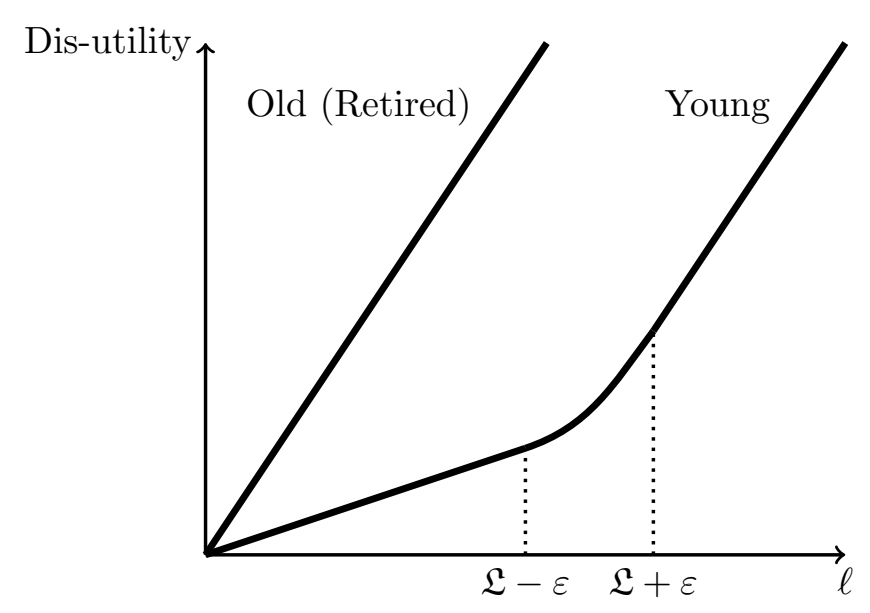

Figure 1: Disutility of LABOR

In the centralized market, a central bank supplies a perfectly storable, divisible, intrinsically 
useless object, called money. The gross growth rate of money is given by $\gamma_{t}=M_{t+1} / M_{t}$, where $M_{t}\left(M_{t+1}\right)$ denotes the stock of money in period $t(t+1)$. Money is injected (withdrawn) through a lump-sum transfer $T_{t}$ to all agents, where $T_{t}=M_{t}-M_{t-1}=\left(\gamma_{t-1}-1\right) M_{t-1}$. Hereafter, we often use $i_{t}=\left(\gamma_{t}-\beta\right) / \beta$ to represent monetary policy, where $i_{t}$ denotes the nominal interest rate on a risk-free one-period bond issued in the centralized market. It is evident that the risk-free nominal interest rate satisfies the Fisher equation, and that the central bank controls $i_{t}$ by choosing $\gamma_{t}{ }^{6}$

Before the goods market opens, young agents receive an idiosyncratic i.i.d. preference shock that determines their ability to produce or consume the specialized good in the goods market: With probability $n$, a young agent can consume but not produce, and with probability $1-n$ he can produce but not consume. For simplicity of the settings, we assume that old agents can consume but not produce in the goods market. ${ }^{7}$ We refer to consumers as buyers and to producers as sellers. The goods market is competitive and agents enjoy utility $u(q)$ from $q$ consumption, where $u^{\prime}(q),-u^{\prime \prime}(q)>0, u^{\prime}(0)=\infty, u^{\prime}(\infty)=0$, and $\alpha(q):=-q u^{\prime \prime}(q) / u^{\prime}(q) \leq 1$ denotes the coefficient of risk aversion of $u(q)$. Sellers incur a utility cost $c(q)=q$ from producing $q$ units of the specialized good. Due to anonymity and the absence of a record-keeping technology, sellers ask for immediate compensation; i.e., a medium of exchange is required and only money can serve this role. Young agents discount between two consecutive periods at the rate $\beta \in(0,1)$. For ease of understanding, Figure 2 shows the timing of events for a

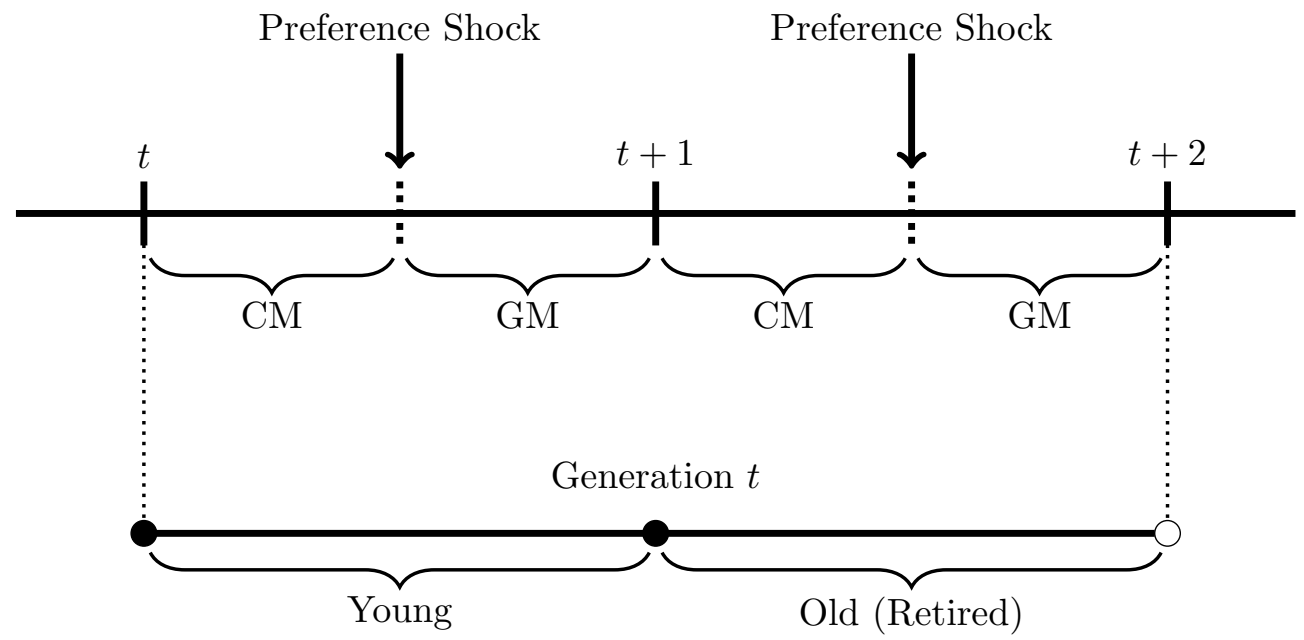

Figure 2: Time Line

representative generation $t$, where $\mathrm{CM}$ denotes centralized market and GM denotes for goods market.

\footnotetext{
${ }^{6}$ We do not incorporate the trading of such a risk-free bond in our model.

${ }^{7}$ Otherwise, some of the old agents would die with money, such that we would need additional settings concerning the lump-sum money transfer (bequests), which do not change our results qualitatively.
} 


\subsection{Planner Allocation}

For a benchmark, it is helpful to derive the planner allocation. The social planner can dictate consumption and production and treats all agents symmetrically. He solves the following decision problem:

$$
\max _{x_{y}, x_{o}, q_{y}, q_{o}} g\left[U\left(x_{y}\right)-f\left[\left(g x_{y}+g_{-1} x_{o}\right) / g\right]+n u\left(q_{y}\right)-(1-n) q^{s}\right]+g_{-1}\left[U\left(x_{o}\right)+u\left(q_{o}\right)\right],
$$

subject to the market clearing constraint, $n g q_{y}+g_{-1} q_{o}=(1-n) g q^{s}$. The planner takes technology and preferences as given, and since young agents suffer a lower disutility of labor than old agents, we impose the assumption, without loss of generality, that only young agents work. The efficient allocation satisfies $u^{\prime}\left(q_{y}\right)=u^{\prime}\left(q_{o}\right)=1$, and $U^{\prime}\left(x_{o}\right)=U^{\prime}\left(x_{y}\right)=f^{\prime}\left[\left(g x_{y}+\right.\right.$ $\left.\left.g_{-1} x_{o}\right) / g\right] \geq 1$.

\section{The Decisions of Generation $t$}

Hereafter, we focus on the decision problem of a representative generation $t$. We first present the last market (goods market) for an old agent in period $t+1$ and then work backwards to the first market (centralized market) for a young agent in period $t$. To economize on notation, we omit the time subscript $t$ going forward. Next-period variables are indexed by +1 , and previous-period variables by -1 .

\subsection{Period $t+1$ : Old Agents}

Goods Market In the goods market, all agents take prices as given. In period $t+1$, every old agent in the goods market buys the specialized good $q_{o,+1}$ at price $p_{+1}$ and enjoys utility $u\left(q_{o,+1}\right)$ from $q_{o,+1}$ consumption. Since an old agent dies at the end of period $t+1$, he will always spend all his money on consumption in this market. Therefore, when he enters the goods market with $m_{o, t+1}$ units of money, his value function equals

$$
W_{o}\left(\phi_{+1} m_{o,+1}\right):=u\left(q_{o,+1}\right), \quad \text { with } \quad m_{o,+1}=p_{+1} q_{o,+1},
$$

where $\phi_{+1}$ is the price of money in terms of centralized market goods in period $t+1$.

Centralized Market In the centralized market, agents can produce and consume the general good $x_{o,+1}$, work $\ell_{o,+1}$, receive the lump-sum money transfer $T_{+1}$, and save $m_{o,+1}$ for consumption in the goods market. An old agent entering the centralized market with $\hat{m}_{o,+1}$ units of money has the value function $V_{o}\left(\phi_{+1} \hat{m}_{o,+1}\right)$ and solves the following decision problem in period $t+1$ :

$$
V_{o}\left(\phi_{+1} \hat{m}_{o,+1}\right):=\max _{x_{o,+1}, \ell_{o,+1}, m_{o,+1}}\left\{U\left(x_{o,+1}\right)-\mu \ell_{o,+1}+W_{o}\left(\phi_{+1} m_{o,+1}\right)\right\}
$$


subject to

$$
x_{o,+1}+\phi_{+1} m_{o,+1}=\ell_{o,+1}+\phi_{+1} \hat{m}_{o,+1}+\phi_{+1} T_{+1} .
$$

Due to the quasi-linear preferences, the choice of $m_{o,+1}$ is independent of $\hat{m}_{o,+1}$ and thus each old agent exits the centralized market with the same amount of money.

\subsection{Period $t$ : Young Agents}

Goods Market In the goods market, a young agent who is a seller with $m_{y}$ units of money has the following decision problem:

$$
W_{y}^{s}\left(\phi m_{y}\right):=\max _{q^{s}}\left\{-q^{s}+\beta V_{o}\left(\phi_{+1} \hat{m}_{o,+1}\right)\right\}
$$

subject to

$$
\hat{m}_{o,+1}=m_{y}+p q^{s},
$$

where $W_{y}^{s}\left(\phi m_{y}\right)$ denotes his value function. Since the goods market is competitive, the price adjusts to equate aggregate demand and aggregate supply. The market clearing condition equals

$$
n g q_{y}+g_{-1} q_{o}=(1-n) g q^{s}
$$

where $n g q_{y}\left(g_{-1} q_{o}\right)$ is the consumed quantity of a young (old) buyer times the number of buyers in his generation, and $(1-n) g q^{s}$ is the produced quantity of a young seller times the number of sellers in his generation.

A young agent who is a buyer with $m_{y}$ units of money has the following decision problem:

$$
W_{y}^{b}\left(\phi m_{y}\right):=\max _{q_{y}}\left\{u\left(q_{y}\right)+\beta V_{o}\left(\phi_{+1} \hat{m}_{o,+1}\right)\right\}
$$

subject to

$$
p q_{y} \leq m_{y}, \quad \text { and } \quad \hat{m}_{o,+1}=m_{y}-p q_{y},
$$

where $W_{y}^{b}\left(\phi m_{y}\right)$ denotes his value function. The first constraint states that a young buyer is constrained by his money holdings, while the second constraint states that the money he brings into the next period, $\hat{m}_{o,+1}$, equals the money he brought into the goods market less the amount he spends on consumption, $m_{y}-p q_{y}$.

Let $W_{y}\left(\phi m_{y}\right)$ denote the value function of a young agent with $m_{y}$ units of money before the realization of the idiosyncratic preference shocks. Then, we have

$$
W_{y}\left(\phi m_{y}\right):=n W_{y}^{b}\left(\phi m_{y}\right)+(1-n) W_{y}^{s}\left(\phi m_{y}\right) .
$$

With probability $n$, an agent becomes a buyer and his value from entering the goods market equals $W_{y}^{b}\left(\phi m_{y}\right)$. With probability $1-n$, he becomes a seller and his value function equals $W_{y}^{s}\left(\phi m_{y}\right)$. 
Centralized Market A young agent entering the centralized market has no endowments, so he faces the following decision problem in period $t$ :

$$
V_{y}:=\max _{x_{y}, \ell_{y}, m_{y}}\left\{U\left(x_{y}\right)-f\left(\ell_{y}\right)+W_{y}\left(\phi m_{y}\right)\right\},
$$

subject to

$$
x_{y}+\phi m_{y}=\ell_{y}+\phi T,
$$

where young agents consume the general good $x_{y}$, work $\ell_{y}$, receive the lump-sum transfer $T$, and save money $m_{y}$ for the future.

\section{Equilibrium}

We focus on symmetric stationary monetary equilibria, where all agents follow identical strategies and real variables are constant over time. We also impose an additional assumption that the population is constant over time; i.e., $g_{t}=1$ for all $t$. In stationary equilibrium, the real stock of money is constant, so that $\phi_{t} M_{t}=\phi_{t+1} M_{t+1}$, which implies

$$
\beta(1+i)=\gamma=\phi / \phi_{+1}
$$

In any monetary equilibrium, we obtain the following two equilibrium conditions from the old agent's decision problem (see Appendix A for their derivation).

$$
\begin{aligned}
u^{\prime}\left(q_{o}\right) & =1+i, \\
U^{\prime}\left(x_{o}\right) & =\mu .
\end{aligned}
$$

Equation (2) is obtained from the envelope condition of an old agent in the goods market. It states that the opportunity cost of holding money, $i$, is equal to the benefit of spending the marginal unit for consumption in the goods market. Equation (3) represents the first-order condition with respect to $x_{o}$ in the centralized market and states that the centralized market consumption of old agents is independent of monetary policy.

The equilibrium conditions of young agents depend on the type of equilibrium which prevails. In what follows, we assume that the critical labor effort, $\mathfrak{L}$, is sufficiently large, such that there is a meaningful difference between young and old agents. Concretely, we assume that $\mathfrak{L}>\mathfrak{L}_{1}(\mu-1):=U^{\prime-1}(1)+u^{\prime-1}(1)-\phi T$ and find that the model features two types of equilibria, which we characterize hereafter. ${ }^{8}$ All proofs are relegated to Appendix A.

\footnotetext{
${ }^{8}$ In Appendix B, we show that when we remove this assumption, i.e., such that young and old agents do not differ much, the model features two additional equilibria, which we label type-III and type-IV equilibrium. In a type-III equilibrium, the cash constraint of a young buyer is binding in the goods market, and young agents work more than $\mathfrak{L}+\varepsilon$, i.e., $\ell_{y}>\mathfrak{L}+\varepsilon$. In a type-IV equilibrium, the cash constraint of a young buyer is binding in the goods market, and young agents work less than $\mathfrak{L}+\varepsilon$ and more than $\mathfrak{L}-\varepsilon$, i.e., $\mathfrak{L}-\varepsilon<\ell_{y}<\mathfrak{L}+\varepsilon$.
} 
Type-I Equilibrium In a type-I equilibrium, the cash constraint of a young buyer is nonbinding in the goods market, and young agents work less than $\mathfrak{L}+\varepsilon$ and more than $\mathfrak{L}-\varepsilon$, i.e., $1<f^{\prime}\left(\ell_{y}\right)<\mu$. A type-I equilibrium is characterized by the following:

Proposition 1 A type-I equilibrium is a list $\left\{q_{o}, q_{y}, x_{o}, x_{y}\right\}$ satisfying (2), (3), and

$$
\begin{aligned}
u^{\prime}\left(q_{y}\right) & =1 \\
U^{\prime}\left(x_{y}\right) & =\mu /(1+i) .
\end{aligned}
$$

Equation (4) states that young buyers consume the efficient quantity $q^{*}$ in the goods market, which solves $u^{\prime}\left(q^{*}\right)=1$. Equation (5) states that the consumption of young agents in the centralized market depends on monetary policy; i.e., the higher the opportunity cost of holding money becomes, the higher centralized market consumption will be. This is because the centralized market consumption of young agents is low in this equilibrium; i.e., we have $\mu /(1+i)=U^{\prime}\left(x_{y}\right)=f^{\prime}\left(\ell_{y}\right) \in(1, \mu)$ by the first-order condition. Hence, a type-I equilibrium does not exist if the opportunity cost of holding money is too large. This is so, because saving for the efficient goods market consumption is too costly when $i$ is large. Under the Friedman rule, $i=0$, the marginal disutility of labor of young agents is equal to that of old agents; i.e., $f^{\prime}\left(\ell_{y}\right)=\mu$. However, if $i>0$, then the marginal disutility of labor of young agents is strictly smaller than that of old agents; i.e., $f^{\prime}\left(\ell_{y}\right)<\mu$. This means that if there is a positive opportunity cost of holding money, young agents optimally choose not to suffer the full marginal disutility of labor in contradiction to old agents. At the same time, they choose to consume more than old agents in the centralized market for any $i>0$; i.e., we have $x_{y}>x_{o}$. There are three unique features of the type-I equilibrium:

- First, young agents save money so that they are prepared not only for their idiosyncratic preference shocks in the goods market, but also for their retirement.

- Second, young agents work more but consume fewer centralized market goods in response to low nominal interest rates, since $\mu /(1+i)=U^{\prime}\left(x_{y}\right)=f^{\prime}\left(\ell_{y}\right)$. This is because young agents prefer to benefit from their lower disutility of labor and the small opportunity cost of holding money. As a result, it could be possible that agents only work when they are young. This would happen, for instance, if $\mathfrak{L}$ is sufficiently large.

- Third, young agents consume the efficient quantity $q^{*}$, but old agents consume less than $q^{*}$; that is, old agents only consume $q_{o}$ in the goods market, where $u^{\prime}\left(q_{o}\right)=1+i$. In the type-I equilibrium, young agents may be able to save enough money to be able to consume $q^{*}$ in the goods market when they are old (for instance, when $\mathfrak{L}$ is very large). However, old agents do not want to consume $q^{*}$, simply because it is not optimal for them. When old, time becomes a more important factor in their decisions. As a result, old agents would prefer to buy more leisure in the centralized market rather than to consume additional goods $q>q_{o}$ in the goods market. More precisely, suppose that an old agent has additional resources to use. The marginal utility of an additional unit of leisure is $\mu>1$. However, 
the marginal utility of an additional unit of consumption, $q>q_{o}$, in the goods market is $u^{\prime}(q) /(\phi p)<u^{\prime}\left(q_{o}\right) /(\phi p)=\mu$, where $\phi p=(1+i) / \mu$ is the relative price of the specialized good with respect to leisure. Therefore, in the type-I equilibrium, young agents consume the efficient quantity $q^{*}$ in the goods market, but old agents optimally choose to consume less than $q^{*}$.

Type-II Equilibrium In a type-II equilibrium, the cash constraint of a young buyer is binding in the goods market, and young agents work less than $\mathfrak{L}-\varepsilon$, i.e., $\ell_{y}<\mathfrak{L}-\varepsilon$. Hence, the marginal disutility of labor of young agents equals $1, f^{\prime}\left(\ell_{y}\right)=1$. A type-II equilibrium is characterized by the following:

Proposition 2 A type-II equilibrium is a list $\left\{q_{o}, q_{y}, x_{o}, x_{y}\right\}$ satisfying (2), (3), and

$$
\begin{aligned}
u^{\prime}\left(q_{y}\right) & =(1+i) /(n \mu)-(1-n) / n, \\
U^{\prime}\left(x_{y}\right) & =1
\end{aligned}
$$

Equation (6) is obtained by rearranging the envelope condition of a young agent entering the goods market. It states that the consumption of young agents is inefficiently low in the goods market. On the contrary, equation (7) shows that the centralized market consumption of young agents is efficient and independent of monetary policy, $U^{\prime}\left(x_{y}\right)=f^{\prime}\left(\ell_{y}\right)=1$. Since $u\left(q_{y}\right)>1$, equation (6) implies that $\mu /(1+i)<1$. Hence, a type-II equilibrium exists only if $i$ is large enough. In this case, young agents optimally choose to consume more goods in the centralized market by reducing their savings for the goods market. In addition, $f^{\prime}\left(\ell_{y}\right)=1<\mu$ implies that young agents optimally choose to minimize the marginal disutility of labor.

\subsection{Regions of Existence}

We now describe the regions of existence of each type of equilibrium. The following proposition characterizes two non-overlapping regions in which these two types of equilibria exist.

Proposition 3 If $i<\mu-1$, equilibrium prices and quantities are characterized by Proposition 1; and if $i>\mu-1$, they are characterized by Proposition 2.

TABle 1: CharaCteristics OF EQUILIBRIA

\begin{tabular}{cccc}
\hline \hline Equilibrium & $q_{y}$ & $x_{y}$ & $\ell_{y}$ \\
\hline Type-I & $q_{y}=q^{*}$ & $U^{\prime}\left(x_{y}\right)=\mu /(1+i)$ & $\mathfrak{L}-\varepsilon<\ell_{y}<\mathfrak{L}+\varepsilon$ \\
Type-II & $q_{y}<q^{*}$ & $U^{\prime}\left(x_{y}\right)=1$ & $\ell_{y}<\mathfrak{L}-\varepsilon$ \\
\hline
\end{tabular}

Table 1 presents the key characteristics of each equilibrium. If the nominal interest rate is low enough, $i<\mu-1$, then the type-I equilibrium exists. Since the opportunity cost of holding money is small in the type-I equilibrium, young agents save money by consuming less in the centralized market, $U^{\prime}\left(x_{y}\right) \geq 1$. Because young agents save enough money, they can consume 
the optimal amount of goods $q_{y}=q^{*}$ if they become buyers. In this type of equilibrium, the opportunity cost of holding money is small, such that it is suboptimal to work less than $\mathfrak{L}-\varepsilon$. Since the marginal disutility of labor would be too high, $f^{\prime}\left(\ell_{y}\right)=\mu$ for $\ell_{y}>\mathfrak{L}+\varepsilon$, young agents choose to work in the range $\mathfrak{L}-\varepsilon<\ell_{y}<\mathfrak{L}+\varepsilon$ in the type-I equilibrium. Equivalently, $1<f^{\prime}\left(\ell_{y}\right)<\mu$. As a result, young agents can still consume more centralized market goods than old agents, because the marginal disutility of labor of young agents is lower than that of old agents, $\mu$. Therefore, we have $x_{y} \geq x_{o}$.

For higher nominal interest rates, $i>\mu-1$, the type-II equilibrium exists. Since the opportunity cost of holding money is high, young agents prefer to consume more centralized market goods, $U^{\prime}\left(x_{y}\right)=1$, by saving less for the goods market. Since they save less, they consume less, $q_{y}<q^{*}$, in the goods market. A high opportunity cost of holding money also results in less work, $\ell_{y}<\mathfrak{L}-\varepsilon$ with $f^{\prime}\left(\ell_{y}\right)=1$, in this type of equilibrium.

\section{Monetary Policy}

We now derive the effect on consumption in each market, $x$ and $q$, in response to a marginal increase in the exogenous policy parameter $i$ in each equilibrium.

Proposition 4 In any type of equilibrium,

$$
\frac{\partial x_{o}}{\partial i}=0, \quad \frac{\partial q_{o}}{\partial i}<0
$$

The general goods consumption of old agents is independent of the nominal interest rate $i$, $U^{\prime}\left(x_{o}\right)=\mu$. Consequently, we have $\partial x_{o} / \partial i=0$. Since $u^{\prime}\left(q_{o}\right)=1+i$, old agents consume less in the goods market $\left(\partial q_{o} / \partial i<0\right)$ when $i$ increases.

Proposition 5 In the type-I equilibrium,

$$
\frac{\partial x_{y}}{\partial i}>0, \quad \frac{\partial q_{y}}{\partial i}=0
$$

In the type-I equilibrium, young agents consume the optimal quantity of specialized goods, $u^{\prime}\left(q^{*}\right)=1$, and thus $\partial q_{y} / \partial i=0$. Since the opportunity cost of holding money is low in the typeI equilibrium, young agents consume a low amount of general goods in the centralized market and save money in order to prepare their retirement. As the opportunity cost of holding money increases, young agents have a lower incentive to save, so they increase their consumption of general goods in the centralized market $\left(\partial x_{y} / \partial i>0\right)$ when $i$ increases.

The relationship between the consumption of general goods, labor, and savings is graphically depicted in Figure 3. The figure shows that young agents save the difference between $\ell_{y}$ and $x_{y}$ for their retirement; i.e., given the budget constraint in the centralized market, we have $\ell_{y}-x_{y}=\phi m_{y}-\phi T$. 


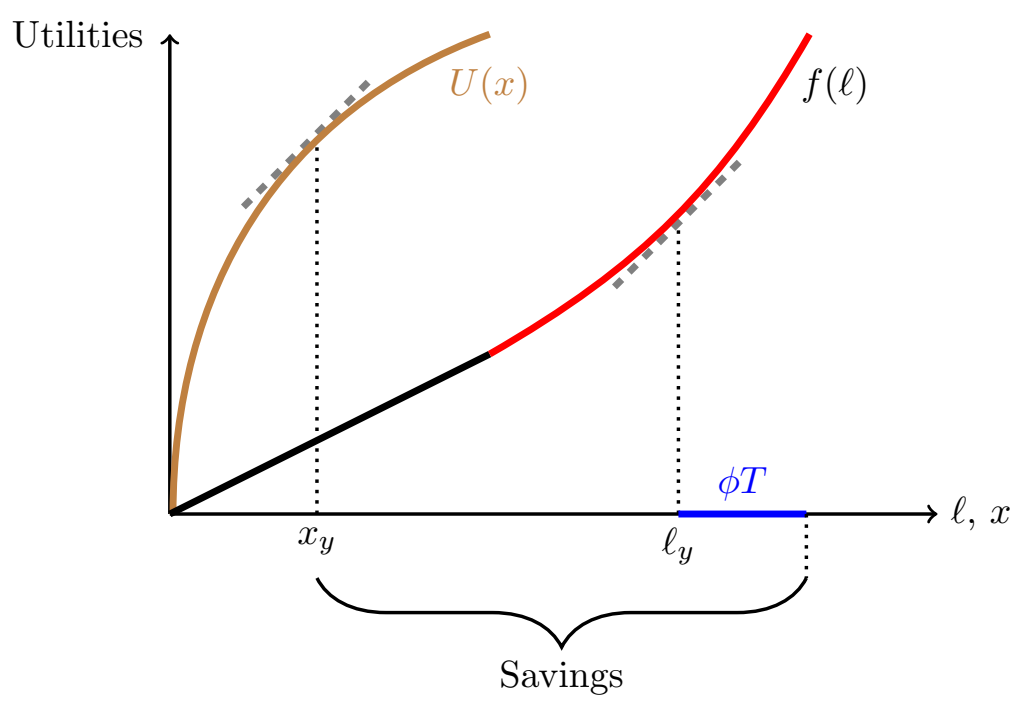

Figure 3: SAVINGS IN THE TYPe-I EQUILIBRIUM

Proposition 6 In the type-II equilibrium,

$$
\frac{\partial x_{y}}{\partial i}=0, \quad \frac{\partial q_{y}}{\partial i}<0 .
$$

In the type-II equilibrium, the opportunity cost of holding money is high. Hence, young agents consume a higher amount of general goods in the centralized market, $U^{\prime}\left(x_{y}\right)=1$, but they cannot consume the optimal amount of specialized goods in the goods market, $q_{y}<q^{*}$. As the opportunity cost of holding money increases, they consume fewer specialized goods in the goods market $\left(\partial q_{y} / \partial i<0\right)$.

It is worth noting that increasing inflation hurts old agents, but benefits young agents in standard overlapping generations models (e.g., Grandmont, 1985). However, we find that this result does not hold anymore in our model when the inflation rate exceeds a certain threshold. In the type-II equilibrium, increasing inflation lowers consumption for both young and old agents. That is, young and old agents do not change the level of their consumption of the general good, but instead reduce their consumption of the specialized good. As a result, increasing inflation hurts both young and old agents in the type-II equilibrium.

The relationship between the consumption of general goods, labor, and savings is graphically depicted in Figure 4. Since $\ell_{y}$ is not determined by $U^{\prime}\left(x_{y}\right)=f^{\prime}\left(\ell_{y}\right)=1$ in the type-II equilibrium, savings cannot be found by means of the budget constraint in the centralized market. Therefore, savings are determined by

$$
u^{\prime}\left(m_{y} / p\right)=u^{\prime}\left(q_{y}\right)=(1+i) / n \mu-(1-n) / n,
$$




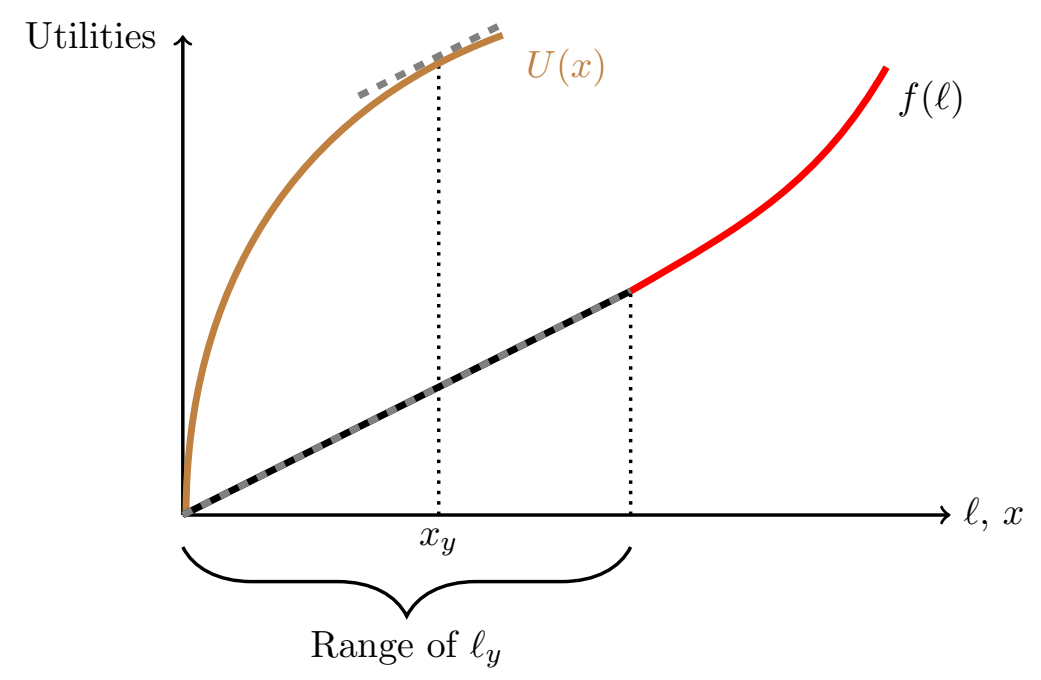

Figure 4: RANGe of $\ell_{y}$ IN THE TYPE-II EQUILIBRIUM

and $\ell_{y}$ is determined by

$$
x_{y}+\phi m_{y}=\ell_{y}+\phi T
$$

i.e., agents only work and save money for their consumption in the period, but not for their retirement.

\subsection{Welfare}

Here, we explain why increasing the exogenous policy parameter $i$ can be welfare-improving. The reason is straightforward. In the type-I equilibrium, centralized market consumption is low, because young agents prefer to save money for their retirement. Increasing $i$ does not affect the goods market consumption of young agents, since they can still consume the optimal amount of goods $q_{y}=q^{*}$. However, it helps to increase the centralized market consumption of young agents, because saving becomes less attractive. The drawback of increasing $i$ is that old agents consume less in the goods market. We show that for low values of $i$, the former effect dominates the latter, such that it is welfare-improving to increase inflation above the Friedman rule.

We follow the literature that builds on Lagos and Wright (2005) and define welfare as the sum of all agents' utilities and dis-utilities from consumption and production of goods. Using the market clearing condition in the goods market, $n q_{y}+q_{o}=(1-n) q^{s}$, the welfare function can be written as follows:

$$
\begin{aligned}
(1-\beta) \mathcal{W} & =\left[U\left(x_{y}\right)-f\left(x_{y}\right)+n u\left(q_{y}\right)-(1-n) q^{s}\right]+\left[U\left(x_{o}\right)-\mu x_{o}+u\left(q_{o}\right)\right] \\
& =\left[U\left(x_{y}\right)-f\left(x_{y}\right)+n u\left(q_{y}\right)-n q_{y}\right]+\left[U\left(x_{o}\right)-\mu x_{o}+u\left(q_{o}\right)-q_{o}\right] .
\end{aligned}
$$


Hence, we can derive

$$
(1-\beta) \frac{\partial \mathcal{W}}{\partial i}=\left[U^{\prime}\left(x_{y}\right)-f^{\prime}\left(x_{y}\right)\right] \frac{\partial x_{y}}{\partial i}+n\left[u^{\prime}\left(q_{y}\right)-1\right] \frac{\partial q_{y}}{\partial i}+\left[u^{\prime}\left(q_{o}\right)-1\right] \frac{\partial q_{o}}{\partial i} .
$$

Proposition 7 It holds that

$$
\frac{\partial \mathcal{W}(0)}{\partial i}>0, \quad \text { and } \quad \frac{\partial \mathcal{W}(i)}{\partial i}<0 \text { for } i>\mu-1 .
$$

If $i$ is sufficiently small, then the economy is in the type-I equilibrium where the level of general goods consumption is low. Especially, at $i=0$, the consumption of general goods is so low that the marginal utility gain from increasing $i$ is significant. If $i$ is larger than $\mu-1$, then the economy is in the type-II equilibrium, where young agents save too little for the goods market. As a result, increasing $i$ is welfare-decreasing, since it decreases the goods market consumption of young and old agents, $\partial q_{y} / \partial i<0$ and $\partial q_{o} / \partial i<0$, while keeping centralized market consumption unchanged, $\partial x_{y} / \partial i=0$. This finding implies that the welfare-maximizing nominal interest rate cannot exceed a certain level. Note that the lump-sum transfer $\phi T$ is not included in equation (8); i.e., the welfare-improving role of inflation has nothing to do with the distributional effect of inflation, which is found in related studies which use overlapping generations models.

\section{Discussion}

Grandmont's (1985) seminal contribution on overlapping generations models is also related to our study. In Grandmont's model, there is a centralized market in each period. Further, he assumes that the marginal utility of young agents is smaller than that of old agents, which guarantees positive savings when agents are young. Grandmont (1985) also finds that output may increase with the inflation rate. However, this result requires a few additional assumptions. First, goods and leisure are assumed to be non-inferior commodities. Second, the marginal propensity to consume leisure is assumed to be higher for old agents than for young agents under any allocation of the real wealth distribution between young and old agents. However, the effects on welfare still remain puzzling under these assumptions.

Compared with Grandmont (1985), our condition concerning the disutility of labor implies his assumption that the marginal utility of young agents is smaller than that of old agents, which is why young agents save for their retirement. In contrast to his study, we do not require any further assumptions in order to obtain an association between increasing centralized market consumption and inflation. This is an important difference, since his additional assumptions are quite strong. That is, his latter assumption is equivalent to assuming that the marginal consumption with respect to real wealth is smaller for old agents than for young agents, independent of their real wealth. ${ }^{9}$ It should therefore be clear that our mechanism is very different

\footnotetext{
${ }^{9}$ In Grandmont (1985), the budget constraint is given by $c_{\tau}\left(a_{\tau}\right)+l_{\tau}^{*}-l_{\tau}\left(a_{\tau}\right)=a_{\tau}$, where consumption $c_{\tau}\left(a_{\tau}\right)$ and labor $l_{\tau}\left(a_{\tau}\right)$ are functions of the real wealth $a_{\tau}$ in each period $\tau$, and $l_{\tau}^{*}$ denotes the endowment of labor.
} 
from Grandmont's approach, where his assumptions drive the results to a large extent. In Table 2, we summarize the main differences between our model and Grandmont's study.

Table 2: Comparison with Grandmont and LW

\begin{tabular}{|c|c|c|c|c|}
\hline \multirow{2}{*}{ Description } & \multicolumn{2}{|c|}{ Our model } & \multirow{2}{*}{ Grandmont } & \multirow{2}{*}{ LW } \\
\hline & Low inflation & High inflation & & \\
\hline Saving for retirement & yes & no & yes & no \\
\hline CM consumption in $i$ & increase & constant & increase $^{\dagger}$ & constant \\
\hline GM consumption in $i$ & decrease & decrease & - & decrease \\
\hline Welfare in $i$ & increase & decrease & - & decrease \\
\hline
\end{tabular}

Additionally, in Table 2 we compare our model with Lagos and Wright (2005). Although we only add one additional assumption to their basic framework, our results are completely different from theirs for low inflation rates. Namely, in our model agents save for their retirement, and centralized market consumption is affected by monetary policy. Some other relationships are the same in both models; for example, agents reduce their goods market consumption as inflation increases. For high inflation rates, our model produces similar results as Lagos and Wright (2005), and hence, also welfare is decreasing in the inflation rate.

\section{Conclusion}

We integrate an overlapping generations model into a new monetarist framework and show that it is welfare-improving to increase inflation above the Friedman rule. This is because inflation makes saving for retirement less attractive, with the result that young agents optimally choose to increase their consumption, while old agents consume less due to the inflation tax. We show that for low inflation rates the former effect dominates the latter, such that it is optimal to increase inflation above the Friedman rule. However, in contrast to standard overlapping generations models, we find that higher inflation rates induce both young and old agents to reduce their consumption. Consequently, the optimal inflation rate must remain beneath a certain threshold level.

By differentiating the budget constraint with respect to real wealth $a_{\tau}$, we can derive $c_{\tau}^{\prime}\left(a_{\tau}\right)-l_{\tau}^{\prime}\left(a_{\tau}\right)=1$; i.e., $\left|l_{\tau}^{\prime}\left(a_{\tau}\right)\right|=-l_{\tau}^{\prime}\left(a_{\tau}\right)=1-c_{\tau}^{\prime}\left(a_{\tau}\right)$. Therefore, Grandmont's assumption on $\left|l_{\tau}^{\prime}\left(a_{\tau}\right)\right|$ is equivalent to an assumption on $c_{\tau}^{\prime}\left(a_{\tau}\right)$; i.e., $\left|l_{2}^{\prime}\left(a_{2}\right)\right|>\left|l_{1}^{\prime}\left(a_{1}\right)\right|$ for any $a_{1}+a_{2}=l_{1}^{*}+l_{2}^{*}$ if, and only if, $c_{2}^{\prime}\left(a_{2}\right)<c_{1}^{\prime}\left(a_{1}\right)$ for any $a_{1}+a_{2}=l_{1}^{*}+l_{2}^{*}$. Especially, $c_{2}^{\prime}(\varepsilon)<c_{1}^{\prime}\left(l_{1}^{*}+l_{2}^{*}-\varepsilon\right)$ for small $\varepsilon$ might be a strong assumption by considering that $c_{2}(0)=0$, and utility is strictly concave in consumption. 


\section{A Appendix: Proofs}

We first derive the solutions to the decision problems of an agent of generation $t$.

In period $t+1$ : In period $t+1$, an agent of generation $t$ is old. The envelope condition of an old agent in the goods market equals

$$
\partial W_{o}\left(\phi_{+1} m_{o,+1}\right) / \partial m_{o,+1}=u^{\prime}\left(q_{o,+1}\right) / p_{+1} .
$$

The above equation simply states that the marginal utility of money for an old agent equals the utility gain from spending the marginal unit on consumption.

The first-order conditions of the centralized market of an old agent with respect to $m_{o,+1}$ and $x_{o,+1}$ are

$$
\partial W_{o}\left(\phi_{+1} m_{o,+1}\right) / \partial m_{o,+1}=\mu \phi_{+1}, \quad \text { and } \quad U^{\prime}\left(x_{o,+1}\right)=\mu .
$$

The first-order condition with respect to $x_{o,+1}$ shows that old agents consume the efficient quantity $x_{o,+1}^{*}$ in the centralized market, which solves $U^{\prime}\left(x_{o,+1}^{*}\right)=\mu$. The term $\partial W_{o}\left(\phi_{+1} m_{o,+1}\right)$ $/ \partial m_{o,+1}$ denotes the marginal benefit from bringing one additional unit of money into the goods market and $\mu \phi_{+1}$ is the marginal cost of doing so. The envelope condition equals

$$
\partial V_{o}\left(\phi_{+1} \hat{m}_{o,+1}\right) / \partial \hat{m}_{o,+1}=\mu \phi_{+1} .
$$

Equation (11) states that the marginal value of money at the beginning of the centralized market equals the price of money in terms of general goods times the marginal disutility of labor of an old agent.

In period $t$ : In period $t$, an agent of generation $t$ is young. The first-order condition of a young seller in the goods market equals

$$
1=\beta p \partial V_{o}\left(\phi_{+1} \hat{m}_{o,+1}\right) / \partial \hat{m}_{o,+1}=\beta p \mu \phi_{+1} ;
$$

i.e., the marginal cost of producing $q^{s}$ units of specialized goods $\left(c^{\prime}\left(q^{s}\right)=1\right)$ equals the price $p$ times the discounted marginal cost of acquiring an additional unit of money in the next period's centralized market. Hence, a young seller is willing to produce the quantity $q^{s}$ that clears the market. A young seller's envelope condition equals

$$
\partial W_{y}^{s}\left(\phi m_{y}\right) / \partial m_{y}=\beta \partial V_{o}\left(\phi_{+1} \hat{m}_{o,+1}\right) / \partial \hat{m}_{o,+1}=\beta \mu \phi_{+1} .
$$

The envelope condition states that a young seller's marginal utility of money equals the marginal value of money at the beginning of the centralized market. This is simply because money has no value to him in the goods market.

The first-order condition and the envelope condition of a young buyer depend on whether his cash constraint is binding or not. If the cash constraint is non-binding, a young buyer is 
able to consume the efficient quantity, such that

$$
u^{\prime}\left(q_{y}\right)=\beta p \partial V_{o}\left(\phi_{+1} \hat{m}_{o,+1}\right) / \partial \hat{m}_{o,+1}=\beta p \mu \phi_{+1}=1 .
$$

In this case, the envelope condition equals

$$
\partial W_{y}^{b}\left(\phi m_{y}\right) / \partial m_{y}=\beta \partial V_{o}\left(\phi_{+1} \hat{m}_{o,+1}\right) / \partial \hat{m}_{o,+1}=\beta \mu \phi_{+1} .
$$

The above equation simply states that the marginal benefit from bringing an additional unit of money into the next period, $\partial W_{y}^{b}\left(\phi_{t} m_{y, t}\right) / \partial m_{y, t}$, equals the discounted marginal cost of acquiring it in the next period's centralized market.

If the cash constraint is binding, we have

$$
p q_{y}=m_{y}, \quad \text { and hence } \quad W_{y}^{b}\left(\phi m_{y}\right)=u\left(q_{y}\right)+\beta V_{o}(0) .
$$

Consequently, the envelope condition equals

$$
\partial W_{y}^{b}\left(\phi m_{y}\right) / \partial m_{y}=u^{\prime}\left(q_{y}\right) / p .
$$

That is, the marginal benefit of money equals the utility of spending the marginal unit on consumption in the goods market.

Finally, the envelope condition of a young agent entering the goods market equals

$$
\partial W_{y}\left(\phi m_{y}\right) / \partial m_{y}=\beta \mu \phi_{+1}=1 / p
$$

if a young buyer's cash constraint is non-binding, and

$$
\partial W_{y}\left(\phi m_{y}\right) / \partial m_{y}=n u^{\prime}\left(q_{y}\right) / p+(1-n) / p,
$$

if the cash constraint is binding.

The first-order conditions with respect to $m_{y}$ and $x_{y}$ of a young agent in the centralized market are

$$
\partial W_{y}\left(\phi m_{y}\right) / \partial m_{y}=\phi f^{\prime}\left(\ell_{y}\right), \quad \text { and } \quad U^{\prime}\left(x_{y}\right)=f^{\prime}\left(\ell_{y}\right) .
$$

The above equations have a similar interpretation as (10).

Derivation of (2). Using the equations (1), (9), (10), (12), we have

$$
u^{\prime}\left(q_{o,+1}\right)=1+i_{+1}
$$

By simply updating the period backwards, we obtain (2).

Derivation of (3). Equation (3) can be obtained from the first-order condition (10) by updating period backward.

Proof of Proposition 1. Derivation of (4). Equation (4) equals the first-order conditions of a young buyer in the goods market when the cash constraint is non-binding, (14).

Derivation of (5). From equation (20), we obtain $\partial W_{y}\left(\phi m_{y}\right) / \partial m_{y}=\phi U^{\prime}\left(x_{y}\right)$. Since a young 
buyer's cash constraint is non-binding in the goods market, the envelope condition of a young agent entering the goods market is given by equation (18). Therefore, we have $U^{\prime}\left(x_{y}\right)=1 /(p \phi)$. Using the equations (1) and (12), we obtain equation (5).

Proof of Proposition 2. Derivation of (6). For a binding cash constraint, the envelope condition of a young agent entering the goods market equals (19). Using this together with equation (20) and the equilibrium condition $f^{\prime}\left(\ell_{y}\right)=1$ to replace $\partial W_{y}\left(\phi m_{y}\right) / \partial m_{y}$, we obtain

$$
-\phi+\left[n u^{\prime}\left(q_{y}\right)+1-n\right] / p=0 .
$$

Using (1) and (12) to replace $p$, and simplifying terms, yields (6).

Derivation of (7). Equation (7) represents the first-order condition (20) in the centralized market of a young agent under the equilibrium condition $f^{\prime}\left(\ell_{y}\right)=1$.

Proof of Proposition 3. The critical value that separates the type-I from the type-II equilibrium requires that (5) and (7) hold simultaneously. Simplifying terms yields $i=\mu-1$.

Proof of Proposition 4. $\partial x_{o} / \partial i$ and $\partial q_{o} / \partial i$ are directly obtained from equations (2) and (3). That is, we obtain

$$
\frac{\partial x_{o}}{\partial i}=0, \quad \frac{\partial q_{o}}{\partial i}=\frac{1}{u^{\prime \prime}\left[u^{\prime-1}(1+i)\right]}<0
$$

Proof of Proposition 5. $\partial x_{y} / \partial i$ and $\partial q_{y} / \partial i$ are directly obtained from equations (4) and (5). That is, we obtain

$$
\frac{\partial x_{y}}{\partial i}=-\frac{\mu}{(1+i)^{2} U^{\prime \prime}\left(U^{\prime-1}[\mu /(1+i)]\right)}>0, \quad \frac{\partial q_{y}}{\partial i}=0 .
$$

Proof of Proposition 6. $\partial x_{y} / \partial i$ and $\partial q_{y} / \partial i$ are directly obtained from equations (6) and (7). That is, we obtain

$$
\frac{\partial x_{y}}{\partial i}=0, \quad \frac{\partial q_{y}}{\partial i}=\frac{1}{n \mu u^{\prime \prime}\left(u^{\prime-1}[(1+i) /(n \mu)-(1-n) / n]\right)}<0
$$

Proof of Proposition 7. Derivation of statement 1. From Proposition 5 and equation (8), we can derive

$$
(1-\beta) \frac{\partial \mathcal{W}}{\partial i}=-\frac{\mu\left[U^{\prime}\left(x_{y}\right)-f^{\prime}\left(x_{y}\right)\right]}{(1+i)^{2} U^{\prime \prime}\left(x_{y}\right)}+\frac{i}{u^{\prime \prime}\left(q_{o}\right)}
$$

At $i=0$, there is no lump-sum transfer $\phi T=0$, which implies $x_{y}<\ell_{y}$ by the budget constraint, 
$x_{y}+\phi m_{y}=\ell_{y}$ with $\phi m_{y}>0$. Hence, we can derive

$$
U^{\prime}\left(x_{y}\right)-f^{\prime}\left(\ell_{y}\right)=0<U^{\prime}\left(x_{y}\right)-f^{\prime}\left(x_{y}\right),
$$

because $f$ is convex and $f^{\prime \prime}\left(\ell_{y}\right)>0$. Therefore, the first term of $(1-\beta) \partial \mathcal{W} / \partial i$ is positive at $i=0$ and the second term vanishes at $i=0$. As a result, we have

$$
\frac{\partial \mathcal{W}(0)}{\partial i}>0
$$

Derivation of statement 2. From Proposition 6 and equation (8), we can derive

$$
(1-\beta) \frac{\partial \mathcal{W}}{\partial i}=\frac{1+i-\mu}{n \mu^{2} u^{\prime \prime}\left(u^{\prime-1}[(1+i) /(n \mu)-(1-n) / n]\right)}+\frac{i}{u^{\prime \prime}\left[u^{\prime-1}(1+i)\right]}<0 .
$$

where both terms are non-positive and cannot be zero at the same time. Therefore, welfare is strictly decreasing in $i$.

\section{B Appendix: Removing the Assumption $\mathfrak{L}>\mathfrak{L}_{1}(\mu-1)$}

\section{B.1 Two Additional Equilibria}

When we eliminate the assumption of $\mathfrak{L}>\mathfrak{L}_{1}(\mu-1)$, we find that the model features two additional equilibria, which we label type-III and type-IV.

Type-III Equilibrium In a type-III equilibrium, the cash constraint of a young buyer is binding in the goods market, and young agents work more than $\mathfrak{L}+\varepsilon$, i.e., $\ell_{y}>\mathfrak{L}+\varepsilon$. Hence, the marginal disutility of labor of young agents equals $\mu, f^{\prime}\left(\ell_{y}\right)=\mu$. A type-III equilibrium is characterized by the following:

Proposition 8 A type-III equilibrium is a list $\left\{q_{o}, q_{y}, x_{o}, x_{y}\right\}$ satisfying (2), (3), and

$$
\begin{aligned}
u^{\prime}\left(q_{y}\right) & =(1+i) / n-(1-n) / n, \\
U^{\prime}\left(x_{y}\right) & =\mu
\end{aligned}
$$

Proof of Proposition 8. Derivation of (21). For a binding cash constraint, the envelope condition of a young agent entering the goods market equals (19). Together with equation (20) and the equilibrium condition $f^{\prime}\left(\ell_{y}\right)=\mu$ to replace $\partial W_{y}\left(\phi m_{y}\right) / \partial m_{y}$, we obtain

$$
-\mu \phi+\left[n u^{\prime}\left(q_{y}\right)+1-n\right] / p=0 .
$$

Using (1) and (12) to replace $p$, and simplifying terms, yields (21).

Derivation of (22). Equation (22) represents the first-order condition (20) in the centralized market of a young agent under the equilibrium condition $f^{\prime}\left(\ell_{y}\right)=\mu$. 
Equation (21) and (22) have a similar interpretation to their counterparts in Proposition 2. However, contrary to the type-I and the type-II equilibrium, a type-III equilibrium can exist for any rate of $i \geq 0$, because $u^{\prime}\left(q_{y}\right)=(1+i) / n-(1-n) / n \geq 1$ for any $i \geq 0$, and the centralized market consumption of young agents is independent of $i$ from equation (22). A typeIII equilibrium is characterized by a low level of consumption in both markets in comparison with the type-I and the type-II equilibrium, because $\mu>\max \{\mu /(1+i), 1\}$ and $(1+i) / n-$ $(1-n) / n>\max \{(1+i) /(n \mu)-(1-n) / n, 1\}$ for any positive $i>0$. Note that, in a type-III equilibrium, the marginal disutility of labor of young agents is equal to the marginal disutility of labor of old agents, $f^{\prime}\left(\ell_{y}\right)=\mu$. This is because consumption in both markets is low, such that young agents endure the full marginal disutility of labor for any $i \geq 0$ in a type-III equilibrium. It is worth mentioning that the type-III equilibrium is an equilibrium that is analyzed in many other studies that build on Lagos and Wright (2005), where the marginal disutility of labor of all agents is identical and constant over time.

Type-IV Equilibrium In a type-IV equilibrium, the cash constraint of a young buyer is binding in the goods market, and young agents work less than $\mathfrak{L}+\varepsilon$ and more than $\mathfrak{L}-\varepsilon$, i.e., $\mathfrak{L}-\varepsilon<\ell_{y}<\mathfrak{L}+\varepsilon$. A type-IV equilibrium is characterized by the following

Proposition 9 A type-IV equilibrium is a list $\left\{q_{o}, q_{y}, x_{o}, x_{y}\right\}$ satisfying (2), (3), and

$$
\begin{aligned}
x_{y} & =f^{\prime-1}\left[U^{\prime}\left(x_{y}\right)\right]-q_{y}(1+i) / \mu+\phi T, \\
U^{\prime}\left(x_{y}\right) & =\left\{n\left[u^{\prime}\left(q_{y}\right)-1\right]+1\right\} \mu /(1+i) .
\end{aligned}
$$

Proof of Proposition 9. Derivation of (23). From equation (20), we obtain $\ell_{y}=f^{\prime-1}\left(U^{\prime}\left(x_{y}\right)\right.$ ). Since the cash constraint is binding, we have (16) and consequently $p q_{y}=m_{y}$. Using equations (1) and (12), we obtain $\phi m_{y}=\phi p q_{y}=q_{y}(1+i) / \mu$. Together with the budget constraint of a young agent entering the goods market,

$$
x_{y}+\phi m_{y}=\ell_{y}+\phi T,
$$

we obtain (23).

Derivation of (24). For a binding cash constraint, the envelope condition of a young agent entering the goods market equals (19). By replacing $\partial W_{y}\left(\phi m_{y}\right) / \partial m_{y}$ in equation (20), we obtain $\phi U^{\prime}\left(x_{y}\right)=n u^{\prime}\left(q_{y}\right) / p+(1-n) / p$. Using (1) and (12) to replace $p$, and simplifying terms, yields (24).

Equation (23) is obtained by rearranging the budget constraint of a young agent in the centralized market. As in the type-I equilibrium, the consumption of young agents in the centralized market increases with the nominal interest rate. However, (24) clearly shows that $x_{y}$ is lower in the type-IV equilibrium than in the type-I equilibrium, since $u^{\prime}\left(q_{y}\right)>1$. 


\section{B.2 Regions of Existence}

We now describe the regions of existence of each type of equilibrium. To do this, we consider a limiting case of $f$ when $\varepsilon$ approaches zero for simplicity of analysis. Note that the regions of existence of each type of equilibrium depend on the nominal interest rate $i$ and the disutility function $f$. However, the function $f$ cannot be described as a one dimensional parameter in general. It is worthwhile noting that the equilibrium conditions in the type-I, II, and III equilibria do not depend on the shape of the function $f$. Thus, this additional simplification will not change our results qualitatively.

Hence, we derive the regions of existence of each type of equilibrium with respect to the nominal interest rate $i$ and the critical labor effort $\mathfrak{L}$. The following proposition guarantees the existence of each type of equilibrium.

Proposition 10 There exist the functions $\mathfrak{L}_{1}(i), \mathfrak{L}_{2}(i), \mathfrak{L}_{3}(i)$, such that

$$
\begin{array}{lll}
\mathfrak{L}_{1}:[0, \mu-1] \rightarrow \mathbb{R}, & \partial \mathfrak{L}_{1}(i) / \partial i>0, & \\
\mathfrak{L}_{2}:[\mu-1, \infty) \rightarrow \mathbb{R}, & \partial \mathfrak{L}_{2}(i) / \partial i<0, & \mathfrak{L}_{2}(\mu-1)=\mathfrak{L}_{1}(\mu-1), \\
\mathfrak{L}_{3}:[0, \infty) \rightarrow \mathbb{R}, & \partial \mathfrak{L}_{3}(i) / \partial i<0, & \mathfrak{L}_{3}(0)=\mathfrak{L}_{1}(0) .
\end{array}
$$

Furthermore,

- the type-I equilibrium is supported if and only if $i<\mu-1$ and $\mathfrak{L}>\mathfrak{L}_{1}(i)$,

- the type-II equilibrium is supported if and only if $i>\mu-1$ and $\mathfrak{L}>\mathfrak{L}_{2}(i)$,

- the type-III equilibrium is supported if and only if $\mathfrak{L}<\mathfrak{L}_{3}(i)$,

- the type-IV equilibrium is supported if and only if $(i) i<\mu-1$ and $\mathfrak{L}_{3}(i)<\mathfrak{L}<\mathfrak{L}_{1}(i)$; or (ii) $i>\mu-1$ and $\mathfrak{L}_{3}(i)<\mathfrak{L}<\mathfrak{L}_{2}(i)$.

Proof of Proposition 10. Derivation of $i=\mu-1$. The critical value that separates the type-I from the type-II equilibrium requires that (5) and (7) hold simultaneously. Simplifying terms yields $i=\mu-1$.

Derivation of $\mathfrak{L}_{1}(i)$. The function $\mathfrak{L}_{1}(i)$ separates the type-I from the type-IV equilibrium. It requires that $(4),(5),(23)$, and $f^{\prime-1}\left[U^{\prime}\left(x_{y}\right)\right]=\ell_{y}=\mathfrak{L}_{1}(i)$ hold simultaneously. Simplifying terms yields

$$
\mathfrak{L}_{1}(i)=U^{\prime-1}[\mu /(1+i)]+u^{\prime-1}(1)(1+i) / \mu-\phi T .
$$

Furthermore,

$$
\frac{\partial \mathfrak{L}_{1}(i)}{\partial i}=-\frac{\mu}{(1+i)^{2}} \frac{1}{U^{\prime \prime}\left(U^{\prime-1}[\mu /(1+i)]\right)}+\frac{u^{\prime-1}(1)}{\mu}>0 .
$$

Derivation of $\mathfrak{L}_{2}(i)$. The function $\mathfrak{L}_{2}(i)$ separates the type-II from the type-IV equilibrium. It requires that $(6),(7),(23)$, and $f^{\prime-1}\left[U^{\prime}\left(x_{y}\right)\right]=\ell_{y}=\mathfrak{L}_{2}(i)$ hold simultaneously. Simplifying 
terms yields

$$
\mathfrak{L}_{2}(i)=U^{\prime-1}(1)+u^{\prime-1}[(1+i) /(n \mu)-(1-n) / n](1+i) / \mu-\phi T .
$$

Furthermore,

$$
\frac{\partial \mathfrak{L}_{2}(i)}{\partial i}=\frac{1+i}{n \mu^{2}} \frac{1}{u^{\prime \prime}\left(q_{y}\right)}+\frac{q_{y}}{\mu}<\frac{1}{\mu}\left[\frac{u^{\prime}\left(q_{y}\right)}{u^{\prime \prime}\left(q_{y}\right)}+q_{y}\right]=\frac{1}{\mu}\left[-\frac{q_{y}}{\alpha\left(q_{y}\right)}+q_{y}\right] \leq 0,
$$

and

$$
\mathfrak{L}_{1}(\mu-1)=\mathfrak{L}_{2}(\mu-1) .
$$

Derivation of $\mathfrak{L}_{3}(i)$. The function $\mathfrak{L}_{3}(i)$ separates the type-III from the type-IV equilibrium. It requires that $(21),(22),(23)$, and $f^{\prime-1}\left[U^{\prime}\left(x_{y}\right)\right]=\ell_{y}=\mathfrak{L}_{3}(i)$ hold simultaneously. Simplifying terms yields

$$
\mathfrak{L}_{3}(i)=U^{\prime-1}(\mu)+u^{\prime-1}[(1+i) / n-(1-n) / n](1+i) / \mu-\phi T .
$$

Furthermore,

$$
\frac{\partial \mathfrak{L}_{3}(i)}{\partial i}=\frac{1+i}{n \mu} \frac{1}{u^{\prime \prime}\left(q_{y}\right)}+\frac{q_{y}}{\mu}<\frac{1}{\mu}\left[\frac{u^{\prime}\left(q_{y}\right)}{u^{\prime \prime}\left(q_{y}\right)}+q_{y}\right] \leq 0
$$

and

$$
\mathfrak{L}_{1}(0)=\mathfrak{L}_{3}(0), \quad \text { and } \quad \mathfrak{L}_{2}(i)>\mathfrak{L}_{3}(i) \text { for any } i \geq \mu-1 .
$$

Figure B.1 shows stylistically the regions of existence as a function of $i$ and $\mathfrak{L}$, while Table B.1 presents the key characteristics of each equilibrium.

Table B.1: Characteristics of Equilibria With $\varepsilon=0$

\begin{tabular}{cccc}
\hline \hline Equilibrium & $q_{y}$ & $x_{y}$ & $\ell_{y}$ \\
\hline Type-I & $q_{y}=q^{*}$ & $U^{\prime}\left(x_{y}\right)=\mu /(1+i)$ & $\ell_{y}=\mathfrak{L}$ \\
Type-II & $q_{y}<q^{*}$ & $U^{\prime}\left(x_{y}\right)=1$ & $\ell_{y}<\mathfrak{L}$ \\
Type-III & $q_{y}<q^{*}$ & $U^{\prime}\left(x_{y}\right)=\mu$ & $\ell_{y}>\mathfrak{L}$ \\
Type-IV & $q_{y}<q^{*}$ & $U^{\prime}\left(x_{y}\right)>1$ & $\ell_{y}=\mathfrak{L}$ \\
\hline
\end{tabular}

Figure B.1 shows that for high values of the critical labor effort, $\mathfrak{L}>\mathfrak{L}_{1}(\mu-1)$, the type-I equilibrium or the type-II equilibrium exist depending on the nominal interest rate. The key features of these two equilibria are described in the main text of this paper. For low values of the critical labor effort, $\mathfrak{L}<\mathfrak{L}_{3}(\infty)$, only the type-III equilibrium exists, independent of the nominal interest rate. In this equilibrium, young agents suffer the same disutility of labor as old agents and thus (i) consume the same amount $x_{y}=x_{o}$ of centralized market goods as old agents do, and (ii) are not able to consume the efficient quantity in the goods market, $q_{y}<q^{*}$. Because the consumption level of young agents is low in both markets, they prefer to work more than the given low value of the critical labor effort. Therefore, we have $\ell_{y}>\mathfrak{L}$ with $f^{\prime}\left(\ell_{y}\right)=\mu$ 


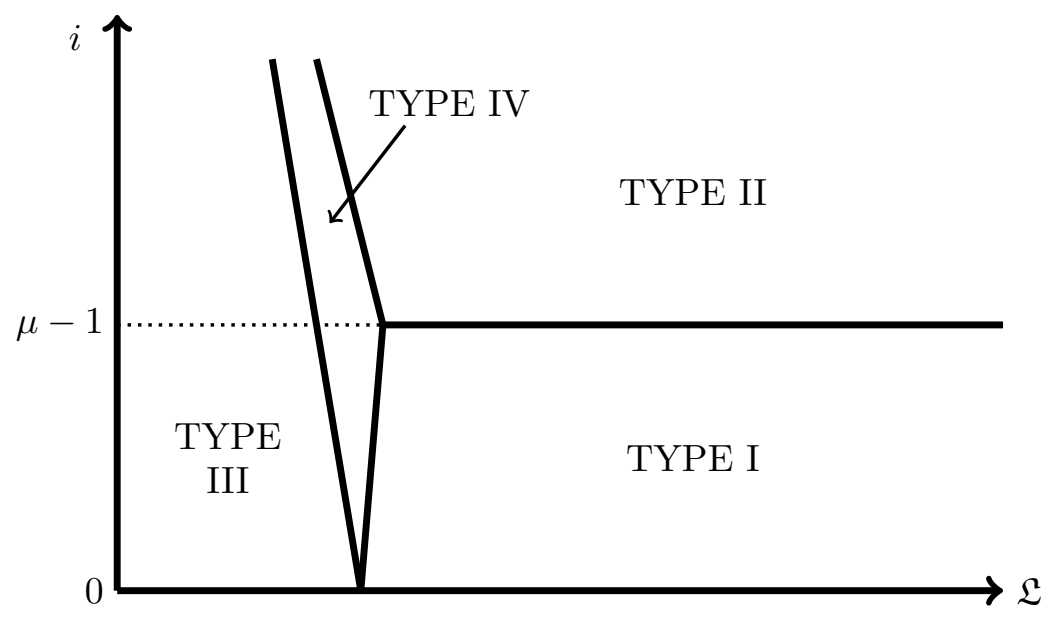

Figure B.1: Regions of Existence With $\varepsilon=0$

in the type-III equilibrium.

The type-IV equilibrium either exists between the type-III and the type-I equilibrium or between the type-III and the type-II equilibrium depending on $i$. The type-IV equilibrium shows mixed characteristics of the other types of equilibria. Concretely, we find that $U^{\prime}\left(x_{y}\right)>1$ in the centralized market similar to the type-I equilibrium, while we obtain $q_{y}<q^{*}$ similar to the type-II and the type-III equilibrium. Figure B.1 shows that for intermediate values of $\mathfrak{L}$, $\mathfrak{L}_{3}(\infty)<\mathfrak{L}<\mathfrak{L}_{1}(\mu-1)$, the sequence of equilibria is either (i) type-III and type-IV, (ii) type-III, type-IV, and type-II, or (iii) type-I, type-IV, and type-II as $i$ increases from 0 to infinity.

\section{B.3 Monetary Policy}

We now derive the effect on the endogenous variables, $x$ and $q$, in response to a marginal increase in the exogenous policy parameter $i$ in the type-III equilibrium.

Proposition 11 In the type-III equilibrium,

$$
\frac{\partial x_{y}}{\partial i}=0, \quad \frac{\partial q_{y}}{\partial i}<0 .
$$

Proof of Proposition 11. $\partial x_{y} / \partial i$ and $\partial q_{y} / \partial i$ are directly obtained from equations (21) and (22). That is, we obtain

$$
\frac{\partial x_{y}}{\partial i}=0, \quad \frac{\partial q_{y}}{\partial i}=\frac{1}{n u^{\prime \prime}\left(u^{\prime-1}[(1+i) / n-(1-n) / n]\right)}<0 .
$$

In the type-III equilibrium, the disutility of labor of young agents is high compared to the other types of equilibria. Hence, young agents only consume the same amount of general goods 
as old agents do. As in the type-II equilibrium, young agents consume less specialized goods in the goods market $\left(\partial q_{y} / \partial i<0\right)$, while keeping the lowest level of general goods consumption $\left(\partial x_{y} / \partial i=0\right)$ when $i$ increases.

\section{B.4 Welfare}

The implications concerning the optimal monetary policy are as follows in the type-III and the type-IV equilibrium.

Proposition 12 In the type-III equilibrium, $\partial \mathcal{W} / \partial i<0$.

Proof of Proposition 12. From Proposition 11 and equation (8), we can derive

$$
(1-\beta) \frac{\partial \mathcal{W}}{\partial i}=\frac{i}{n u^{\prime \prime}\left(u^{\prime-1}[(1+i) / n-(1-n) / n]\right)}+\frac{i}{u^{\prime \prime}\left[u^{\prime-1}(1+i)\right]} \leq 0,
$$

where both terms are strictly negative if $i>0$. Therefore, welfare is strictly decreasing in $i>0$.

In the type-III equilibrium, $\mathfrak{L}$ is small such that young agents face the same marginal disutility of labor as old agents do. Proposition 12 confirms that the type-III equilibrium shows the standard characteristics of many other models that build on Lagos and Wright (2005).

The type-IV equilibrium shows mixed characteristics of the other types of equilibria.

\section{References}

Bhattacharya, J., Haslag, J., and Martin, A., 2005, "Heterogeneity, Redistributions, and the Friedman Rule", International Economic Review, 46, 437-454.

Berentsen, A., Camera, G., and Waller, C., 2005, "The Distribution of Money Balances and the Nonneutrality of Money", International Economic Review, 46, 465-487.

Berentsen, A., Rocheteau, G., and Shi, S., 2007, "Friedman Meets Hosios: Efficiency in Search Models of Money", The Economic Journal, 117, 174-195.

Bewley, T., 1980, "The Optimum Quantity of Money", in Models of Monetary Economics, ed. by John Kareken and Neil Wallace, Minnesota: Federal Reserve Bank.

Bewley, T., 1983, "A Difficulty with the Optimum Quantity of Money", Econometrica, 51, $1485-1504$.

Chiu, J., and Molico, M., 2010, "Liquidity, Redistribution, and the Welfare Cost of Inflation", Journal of Monetary Economics, 57, 428-438.

Chiu, J., and Molico, M., 2011, "Uncertainty, Inflation, and Welfare", Journal of Money, Credit and Banking, 43, 487-512. 
Chiu, J., and Molico, M., 2014, "Short-Run Dynamics in a Search-Theoretic Model of Monetary Exchange", Working Paper.

Cooley, T. F., and Quadrini, V., 2004, "Optimal Monetary Policy in a Phillips-Curve World", Journal of Economic Theory, 118, 174-208.

Deviatov, A., and Wallace, N., 2001, "Another Example in which Lump-sum Money Creation is Beneficial", Advances in Macroeconomics 1, Article 1.

Friedman, M.,1969, "The Optimum Quantity of Money", in M. Friedman The Optimum Quantity of Money and Other Essays, Aldine, Chicago, 1-50.

Gomis-Porqueras, P., and Sanches, D., 2013, "Optimal Monetary Policy in a Model of Money and Credit", Journal of Money, Credit and Banking, 45, 701-730.

Grandmont, J. M., 1985, "On Endogenous Competitive Business Cycles", Econometrica, 53, 995-1045.

Kehoe, T. J., Levine, D. K., and Woodford, M., 1992, "The Optimum Quantity of Money Revisited", in P. Dasgupta et al., eds., Economic Analysis of Market Games: Essays in Honor of Frank Hahn (Cambridge, MA, and London: MIT Press), 501-526.

Lagos, R., and Wright, R., 2005, "A Unified Framework for Monetary Theory and Policy Evaluation", Journal of Political Economy, 113, 463-484.

Levine, D., 1991, "Asset Trading Mechanisms and Expansionary Policy", Journal of Economic Theory, 54, 148-164.

Menzio, G., Shi, S., and Sun, H., 2013, "A Monetary Theory with Non-Degenerate Distribution", Journal of Economic Theory, 148, 2266-2312.

Molico, M., 2006, "The Distribution of Money and Prices in Search Equilibrium", International Economic Review, 47, 701-722.

Rocheteau, G., and Rodriguez-Lopez, A., 2014, "Liquidity Provision, Interest Rates, and Unemployment", Journal of Monetary Economics, 65, 80-101.

Rocheteau, G., and Wright, R., 2005, "Money in Search Equilibrium, in Competitive Equilibrium, and in Competitive Search Equilibrium", Econometrica, 73, 175-202.

Rocheteau, G., and Wright, R., 2009, "Inflation and Welfare in Models with Trading Frictions", in Monetary Policy in Low Inflation Economies, ed. by Ed Nosal and Dave Altig, Cambridge University Press.

Rocheteau, G., Weill, P. O., and Wong, T. N., 2015a, "A Tractable Model of Monetary Exchange with Ex-Post Heterogeneity", Working Paper. 
Rocheteau, G., Weill, P. O., and Wong, T. N., 2015b, "Working Through the Distribution: Money in the Short and Long Run", Working Paper.

Schreft, S., and Smith, B., 1997, "Money, Banking, and Capital Formation", Journal of Economic Theory, 73, 157-182.

Schreft, S., and Smith, B., 2002, "The Conduct of Monetary Policy with a Shrinking Stock of Government Debt", Journal of Money, Credit and Banking, 34, 848-882.

Shi, S., 1997, "A Divisible Search Model of Fiat Money", Econometrica, 65, 75-102.

Smith, B., 2002, "Monetary Policy, Banking Crises, and the Friedman Rule", American Economic Review, 92, 128-134.

Williamson, S., 2006, "Search, Limited Participation, and Monetary Policy", International Economic Review, 47, 107-128.

Zhu, T., 2008, "An Overlapping-Generations Model with Search", Journal of Economic Theory, $142,318-331$. 